\title{
Posting versus Replying: The Effects of Instructor Participation in MOOC Discussion Forums
}

\author{
Zhao Du \\ Business School of Sport, \\ Beijing Sport University \\ duzhao@bsu.edu.cn
}

\author{
Fang Wang \\ Lazaridis School of Business \\ \& Economics, \\ Wilfrid Laurier University \\ fwang@wlu.ca
}

\author{
Shan Wang \\ Department of Finance and \\ Management Science, \\ University of Saskatchewan \\ wang@edwards.usask.ca
}

\begin{abstract}
Previous research has suggested that the frequency of instructor participation in online discussion forums can affect student participation and subsequently their learning results in online courses. However, the different approaches of instructor participation and their effects have not been well studied, particularly in MOOCs of very large class sizes. This research investigates how instructor participation via posting vs. replying in online discussion forums affects student participation in MOOCs. Our results show that instructors mainly participate through replying rather than posting. However, instructor posting is more effective than instructor replying on enhancing student participation, and this advantage of instructor posting over replying increases with class size. Class size negatively moderates the positive effect of instructor replying, but not that of instructor posting. These findings implicate the necessity of a well-planned participation strategy for instructors to engage in MOOC discussion forums.
\end{abstract}

\section{Introduction}

Asynchronous online discussion forums are a standard setup in online courses including remote teaching courses and Massive Open Online Courses (MOOCs). Through online discussion forums, students interact with peers and instructors, which is otherwise lacking in the online education setups but critical in student learning experience and for enhancing learning outcomes [1-2]. However, student participation in online discussion forums is often insufficient [3-8]. It is observed that only a small percentage of students post in e-learning forums and their participation is not consistent and sustained throughout an online course [910]. Educators and researchers continuously seek to understand how to increase student participation in online discussion forums [9, 11-12].
Instructor participation is a common approach adopted for improving student participation [1-2]. However, prior research shows that the effects of instructor participation on student participation can vary significantly across educational scenarios, with both positive and negative results [13-16]. As participating in online forums takes significant time and efforts of instructors, it is important to understand contextual conditions and instructor strategies that may facilitate and enable the positive effects of instructor participation. In this line of studies, Parks-Stamm, Zafonte, and Palenque [17] indicate that the positive effect of instructor participation on student participation is moderated by class size; the effect is significant in small classes of less than 15 students, but insignificant in medium size classes with 15-30 students.

Although existing literature provides useful insights into the relationship between instructor participation and student participation in online course discussion forums, two limitations warrant further investigation. First, most research studied instructor participation through the frequency of their online forum activities without differentiating the types of activities $[1,17]$. Instructors can participate in online forums by contributing new posts to lead student discussion or by replying and responding to student posts. These different ways of participation may manifest instructor presence and serve instruction functions differently [18-19], thus may have varying effects on student participation. Detangling instructor participation in online discussion forums to posting and replying activities and studying their separate effects on student participation could provide additional insights on instructor participation activities and effects.

Second, the knowledge on the effect of instructor participation on student participation is largely developed within online courses of limited class size, i.e., less than 50 students $[1,17,19-20]$. It is unclear whether the effect may manifest in classes of very large size, such as MOOCs, especially as class size is shown 
to negatively moderate the effect of instructor participation [17]. Moreover, the massive class size and diverse student backgrounds in MOOCs can complicate the demands, efforts, and results of instructor participation [9, 21]. As MOOCs become a popular mode of e-learning, it is important to understand the effect of instructor participation in this context.

To fill the knowledge gaps in the extant literature on the different approaches of instructor participation in online discussion forums and their effects in MOOCs, this research investigates the following questions through class level analysis: (1) Does instructor participation affect student participation in MOOCs of very large class size? (2) How do instructors' posting (i.e., initiating new threads of discussion) and replying (i.e., responding to student posts) differentially affect student participation in online discussion forums? and (3) How does class size moderate the effects of instructor posting and instructor replying, respectively, on student participation?

\section{Literature review}

\subsection{Instructor participation and student participation in online discussion forums}

Asynchronous discussion via online forums is a core element of e-learning. It is essential to the collaborative learning among students and alleviates the problem of limited interactivity associated with videobased remote course delivery $[9,11,22]$. Participation in online forums of a course can promote knowledge construction, critical thinking, and problem-solving [23], thus enhancing learners' course completion, learning performance, and experience [24-26]. However, students often have inadequate participation in online discussion forums $[5,7-8,11]$. Consequently, research has investigated a wide range of factors and methods that can promote student participation. These include instructor participation and interaction [1-2], student facilitators [27], computer-supported cooperative learning strategies [12], and other individuals, social, pedagogical, and technological factors [28].

Instructor participation in online discussion forums is a commonly adopted instructional strategy to engage students and enhance their participation [18-19]. This effect has been mainly studied in the context of online courses of limited class size [13-14, 16-17]. In general, students prefer instructors' presence in online discussion forums and desire instructor-led discussions because instructor participation provides content expertise, focus of discussion, and a sense of community [13, 29-30]. However, students may sometimes find instructor presence authoritarian or intimidating, limiting their participation $[15,31]$. Consequently, prior research using on online discussion forum data and survey studies has revealed mixed results on the effect of instructor participation. Some studies report positive effects of instructor participation on student participation [13-14, 16], some find no effects [32-33], yet others suggest negative effects [15, 34]. ParksStamm, Zafonte, and Palenque [17] suggest that class size can negatively moderate the positive effect of instructor participation. In their sample, the positive effect of instructor participation is significant in small classes of less than 15 students but insignificant in medium-size classes with 15-30 students.

Besides the frequency of instructor participation, research through student surveys has inquired into different types of instructor interaction. For example, Kang and Im [3] identified and studied multiple types of students' perceived instructor interaction, including guidance and facilitating learning, social intimacy, instructional communication, presence of an instructor, and instructional support, and social interaction, in online forums. Generally, it is found that instructional interaction of instructors can enhance students' perception of their learning, conversational interaction can improve students' perceptions of instructor and course quality, and social interaction elements such as social intimacy could negatively affect perceived learning achievement and satisfaction [3, 18-19].

Collectively, prior research indicates variations in the frequency and content of instructor participation in online discussion forums and has studied their effects in relatively small-size classes. It specifies the need for instructors to plan and structure their participation and interaction in online discussion forums as part of the curriculum development beforehand so they can effectively and efficiently engage students to enhance student learning experience [18]. Research has not separately studied instructor posting and replying, and the negative moderation of class size on the positive effect of instructor participation on student participation raises a question on the sustainability of the effect in large-size classes.

\subsection{MOOCs}

Offering unlimited participation and open access to online education, MOOCs are a prominent trend in recent online education and have gained increased popularity in the past decade [35]. Different from traditionally studied online courses of limited class size, MOOCs are typical of a very large class size, ranging from thousands to hundreds of thousands of registered learners in a course session. The open access and large class size are associated with an ultra-high student-toinstructor ratio and low course completion [35-36]. 
MOOCs mainly rely on video-based course delivery, which is complemented by peer and studentinstructor interactions in online discussion forums. Similar to online courses of smaller sizes, student participation in MOOC discussion forums significantly contributes to their learning experience and performance [2, 9, 21, 37]. However, the MOOC settings of large class sizes and diverse student backgrounds pose unique challenges to both student and instructor participations in online forums. Typically, $5 \%-25 \%$ of students of MOOCs post in online discussion forums [9-10], and student posts are often not cohesive [38].

To motivate student participation, research on MOOCs has discussed and experimented with several IT-design oriented approaches, including incentive mechanisms such as badges and reputation systems [39], automatic reminding emails [40], and postrecommendation algorithms that recommend post threads to students [41]. For example, Howley et al. studied the effect of reputation systems on help-seeking in MOOC discussion forums and found that up/downvoting harms help-seeking, which is mitigated by the positive effect of Help Giver badges [39]. While proposed and tested, these methods have not been commonly deployed in MOOC platforms [9].

Overall, the low participation rates and the difficulties in motivating sustained participation in MOOCs point to the strong need for instructors' guidance and involvement. However, instructor participation and its effects in MOOCs are rarely studied and not confirmed.

\section{Theoretical development and hypotheses}

This research studies the modality of instructor participation on online discussion forums via posting and replying. Instructors participate in online discussion forums in two ways: posting a question or comment for students to reply, or replying to student posts. Instructors have a wide range of personal preferences over these two ways of online forum participation, some only posting questions to start new threads of discussion, some only responding to student posts, and most using both in a combination. This research examines how the two modes of instructor participation in online learning forums affect student participation and how class size moderates their respective effects. Figure 1 presents the research framework.

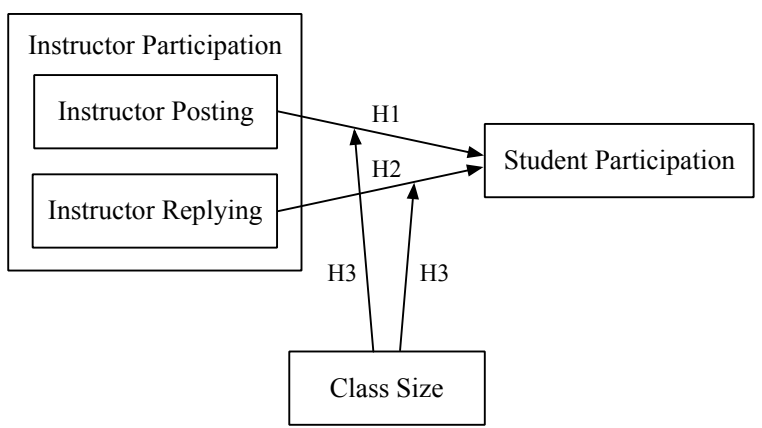

Figure 1. Research framework

Instructor posting represents instructors' proactive participation in online discussion forums and their leading student discussions. These posts start new threads of discussion that are open to all students to reply to. In online discussion forums, instructor posts easily stand out from student posts to attract student attention, provide strong instructional content and direction of learning, and manifest instructor presence. These posts either complement video materials or address general issues promptly to help student learning. Students can be effectively guided and motivated by instructors' direction and presence [18-19], leading to their enhanced involvement in online discussion.

Comparatively, instructor replying represents instructors' reactive participation in online forums and their effort in addressing individual question and comment of students. As instructor replies are embedded under student posts, this type of instructor participation could be less visible than instructor posts to the class. Student posts often reflect pragmatic issues and challenges they encounter in their learning process. These issues may or may not be representative. Replying to student posts may effectively help students in addressing individual issues, demonstrate instructors' accessibility and involvement with online discussion, and reduce the social distance between instructors and students.

Considering that instructors can manifest their presence, direct online discussion, and motivate students through both posting and replying in online discussion forums, we test:

\section{H1: Instructor participation through posting enhances student participation in online discussion forums.}

H2: Instructor participation through replying enhances student participation in online discussion forums.

Additionally, we posit the heterogeneous effects of instructor posting and replying on student participation 
across different class sizes. As class size increases (or decreases), the effects of instructor posting and replying may vary because of the different prominence and value of instructor posting and replying to students. When class size increases, post volume and content diversity in discussion forums increase [42-43]. Students need to be more selective to online discussion contents, thus may be more appreciative and responsive to instructor posts that are prominent and contain high-quality learning relevant content. Meanwhile, as post volume and content diversity increase, instructor replies to individual student posts may become less exposed to the class and diluted in their value. We test,

H3: Class size moderates the effects of instructor posting and instructor replying on student participation in online discussion forums. The moderation effects differ between instructor participation through posting and that through replying.

\section{Method}

\subsection{Data}

We obtained a large-scale proprietary dataset from is a leading MOOC platform in China. Similar to Coursera in the U.S., it offers undergraduate-level MOOCs across mutiple disciplines to the students in Chinese colleges and universities as well as the public. The majority of the courses are taught by professors in Chinese colleges and universities. Courses are offered in consecutive sessions/classes, usually one session at a time.

The majority of courses on the MOOC platform are offered in Chinese, but some are in English. For the empirical study, we focus on courses in Chinese. Chinese is the native language of most instructors and students on the MOOC platform and does not present language constraints that may affect online forum participation. In addition, courses on the MOOC platform are of a wide range of duration, spanning from 11 days to 1,095 days. To reduce the heterogeneity of instructor and student participation associated with a wide range of course duration, we focus on courses with a duration between 6 weeks and 4 months. This range of course duration is within those of half-term and fullterm courses in traditional university settings, thus provides a more common learning context for studying online forum participation.

The final dataset for analysis consists of 16,748 classes of 4,629 MOOCs. It contains 194,458 instructor posts, 1,764,728 instructor replies, and a total of $62,475,052$ student posts and replies.

\subsection{Variables and descriptive statistics}

Table 1 summarizes the definitions and operationalization of the variables in this study. The dependent variable in this study is student participation (StudentPart). The independent variables under study include instructor participation (InstructorPart), instructor posting (InstructorPost), and instructor replying (InstructorReply). The moderator under study is class size (ClassSize).

Table 1. Variable definition and operationalization

\begin{tabular}{ll}
\hline Variable & \multicolumn{1}{c}{ Definition and operationalization } \\
\hline Dependent variable \\
\hline StudentPart & $\begin{array}{l}\text { The level of student participation in a } \\
\text { class of a course, which is measured by } \\
\text { the average number of online discussion } \\
\text { forum activities (including both posting } \\
\text { and replying) per week per student in a } \\
\text { class of a course. }\end{array}$ \\
\hline
\end{tabular}

Independent variables

InstructorPart The level of instructor participation in a class of a course, which is measured by the average number of posts and replies per week published by an instructor in the online discussion forum of a class of a course.

InstructorPost The level of instructor posting in a class of a course, which is measured by the average number of (new) posts per week published by an instructor in the online discussion forum of a class of a course.

InstructorReply The level of instructor replying in a class of a course, which is measured by the average number of replies per week published by an instructor in the online discussion forum of a class of a course.

\begin{tabular}{ll}
\hline Moderator & \\
\hline ClassSize & $\begin{array}{l}\text { Class size, which is measured by the } \\
\text { number of registered learners in a class } \\
\text { of a course. }\end{array}$ \\
\hline
\end{tabular}

Control variables

ClassDuration Indicates the class duration. It is operationalized as the number of days between the start and the end of a class of a course.

ClassNo Indicates the sequential number of a class in the course offerings. It is operationalized as dummy variables representing the sequence of a class of a course. In particular, the ClassNo for the first class of a course is 1 , the ClassNo for the second class of a course is 2 , and 
so on.

ClassStartYM Indicates the year and month that a class of a course starts. It is operationalized as dummy variables denoting the year and month in which a class of a course starts.

ClassStartDoW Indicates the day of week that a class of course starts. It is operationalized as dummy variables denoting the day of a week on which a class of a course starts.

Table 2 presents the descriptive statistics of the variables. Overall, student participation in online discussion forums is low, with the average weekly activity per student (including both posting and replying) being only 0.05 . This is in line with previous findings on the low student participation in online learning forums, particularly in the MOOC setting [3-6, 9-10, 38]. Instructors participate mostly by replying to student posts, which consists of $90 \%$ of the instructor participation activities. The average weekly instructor posting is about 1, whereas the average weekly instructor replying amounts to about 9 . Instructors are more responsive to student posts than being proactive in directing discussion in their online forum participation. The average class size of MOOCs in our sample is 8,210 students, and the largest class consists of over 761 thousand students. This differentiates from the online courses studied in prior literature on instructor participation [1, 17, 19-20]. The average length of courses in our sample is about 90 days, i.e., about three months.

Table 2. Descriptive statistics

\begin{tabular}{lccccc}
\hline \multicolumn{1}{c}{ Variable } & \multirow{N}{*}{$\mathrm{N}$} & Mean & $\begin{array}{c}\text { Std. } \\
\text { Dev. }\end{array}$ & Min. & Max. \\
\hline StudentPart & 16,748 & 0.05 & 0.17 & 93 & 5.55 \\
InstructorPart & 16,748 & 9.50 & 31.55 & 0 & $1,024.29$ \\
InstructorPost & 16,748 & 0.95 & 1.30 & 0 & 19.90 \\
InstructorReply & 16,748 & 8.54 & 31.29 & 0 & $1,021.52$ \\
ClassSize & 16,748 & 8,210 & 18,75 & 0 & 761,601 \\
ClassDuration & 16,748 & 89.75 & 20.25 & 11 & 119 \\
\hline
\end{tabular}

\subsection{Empirical model}

We use class-level fixed-effects regression analysis to test the hypotheses. Fixed-effects regression is a common approach used to analyze panel data. It is capable of capturing unobserved heterogeneity across samples that are fixed over the different observation points [44]. Natural logarithm transformation is taken when a variable is highly skewed. The regression model is specified in equation (1):

$$
\begin{gathered}
\text { InStudentPart }_{i}=\beta_{0}+\beta_{1} \text { lnInstructorPost }_{i}+ \\
\beta_{2} \text { InInstructorReply }_{i}+\beta_{3} \text { InInstructorPost }_{i} \times \\
\text { InClassSize }_{i}+\beta_{4} \text { InInstructorReply }_{i} \times \\
\text { lnClassSize }_{i}+\beta_{5} \text { lnClassSize }_{i}+ \\
\beta_{6} \text { ClassDuration }_{i}+\beta_{7} \text { ClassNo }_{i}+ \\
\beta_{8} \text { ClassStartYM }_{i}+\beta_{9} \text { ClassStartDoW }_{i}+\varepsilon_{i}
\end{gathered}
$$

where the subscript $i$ indicates a MOOC class.

\section{Results}

We conduct the data analysis using Stata 15 [45]. Table 3 presents the estimation results of the regression analyses. Models (1) and (2) analyze the effect of instructor participation, measured by the total number of weekly activities of posting and replying, on student participation. Models (3) and (4) analyze the separate effects of instructor posting and instructor replying on student participation. Model (5) is a post-analysis on the effect of class size. These models received good fits [46] with adjusted $R$-squared values ranging from 0.17 to 0.20 . These indicate that $17 \%$ to $20 \%$ of the variance for the dependent variable is explained by independent variables in the models.

As shown in models (1) and (2), instructor participation positively affects student participation ( $\beta=0.145$ in model (1)), and class size negatively moderates the positive effect of instructor participation on student participation ( $\beta=-0.017$ in model (2)). As class size increases, the positive effect of instructor participation on student participation decreases. These results are consistent with those of prior studies on small online courses [13-14, 16-17]. The effect of instructor participation on student participation is confirmed in MOOCs of massive class sizes.

The results in models (3) and (4) pertain to hypothesis testing and provide interesting insights. Model (3) partitions instructor participation into posting and replying, and tests their effects separately. The parameter estimation of lnInstructorPost is significantly positive $(\beta=0.134)$, indicating that instructor posting increases student participation. $\mathrm{H} 1$ is supported. The parameter estimation of InInstructorReply is also significantly positive $(\beta=$ $0.116)$, indicating that instructor replying to student posts increases student participation. H2 is supported. A $z$-test confirms that the estimations of InInstructorPost is different from that of InInstructorReply, suggesting that the effect of instructor posting on student participation is stronger than that of instructor replying. 
Table 3. Estimation results of the regression analyses

\begin{tabular}{|c|c|c|c|c|c|}
\hline & (1) & (2) & (3) & (4) & (5) \\
\hline InInstructorPart & $\begin{array}{c}0.145 * * * \\
(0.005)\end{array}$ & $\begin{array}{c}0.283 * * * \\
(0.027)\end{array}$ & & & $\begin{array}{c}0.212 * * * \\
(0.029)\end{array}$ \\
\hline InInstructorPost & & & $\begin{array}{c}0.134 * * * \\
(0.007)\end{array}$ & $\begin{array}{c}0.098^{* * *} \\
(0.035)\end{array}$ & \\
\hline InInstructorReply & & & $\begin{array}{c}0.116^{* * *} \\
(0.005)\end{array}$ & $\begin{array}{c}0.259^{* * *} \\
(0.028)\end{array}$ & \\
\hline $\begin{array}{l}\text { InInstructorPart } \\
\times \text { lnClassSize }\end{array}$ & & $\begin{array}{c}-0.017 * * * \\
(0.003)\end{array}$ & & & $\begin{array}{c}-0.008^{* *} \\
(0.003)\end{array}$ \\
\hline $\begin{array}{l}\text { InInstructorPost } \\
\times \operatorname{lnClassSize}\end{array}$ & & & & $\begin{array}{c}0.004 \\
(0.004)\end{array}$ & \\
\hline $\begin{array}{l}\text { InInstructorReply } \\
\times \operatorname{lnClassSize}\end{array}$ & & & & $\begin{array}{c}-0.017 * * * \\
(0.003)\end{array}$ & \\
\hline InClassSize & $\begin{array}{l}0.023^{*} \\
(0.012)\end{array}$ & $\begin{array}{c}0.041 * * * \\
(0.013)\end{array}$ & $\begin{array}{c}0.026^{* *} \\
(0.012)\end{array}$ & $\begin{array}{c}0.045^{* * *} \\
(0.014)\end{array}$ & $\begin{array}{c}0.571 * * * \\
(0.088)\end{array}$ \\
\hline $\operatorname{lnClassSize} e^{2}$ & & & & & $\begin{array}{c}-0.031 * * * \\
(0.005)\end{array}$ \\
\hline ClassDuration & $\begin{array}{c}-0.004 * * * \\
(0.000)\end{array}$ & $\begin{array}{c}-0.004 * * * \\
(0.000)\end{array}$ & $\begin{array}{c}-0.003 * * * \\
(0.000)\end{array}$ & $\begin{array}{c}-0.003 * * * \\
(0.000)\end{array}$ & $\begin{array}{c}-0.004 * * * \\
(0.000)\end{array}$ \\
\hline $\begin{array}{l}\text { ClassNo } \\
\text { (fixed effect) }\end{array}$ & Yes & Yes & Yes & Yes & Yes \\
\hline $\begin{array}{l}\text { ClassStartYM } \\
\text { (fixed effect) }\end{array}$ & Yes & Yes & Yes & Yes & Yes \\
\hline $\begin{array}{l}\text { ClassStartDoW } \\
\text { (fixed effect) }\end{array}$ & Yes & Yes & Yes & Yes & Yes \\
\hline \# observations & 16,748 & 16,748 & 16,748 & 16,748 & 16,748 \\
\hline Adjusted $R^{2}$ & 0.166 & 0.168 & 0.193 & 0.195 & 0.171 \\
\hline
\end{tabular}

Note: $* p<0.1 ; * * p<0.05 ; * * * p<0.01$

Model (4) examines H3 through the interaction terms of instructor participation activities and class size. The parameter of the interaction term (lnInstructorPost $\times$ lnClassSize) is insignificant, indicating no moderation of class size on the effect of instructor posting. That is, the positive effect of instructor posing on student participation is consistent across various class sizes. In contrast, the parameter estimation of lnInstructorReply $\times$ lnClassSize is significantly negative $(\beta=-0.017)$, indicating the negative moderation of class size on the positive effect of instructor replying on student participation. Relating this result to that of model (2) reveals that the negative moderation effect of class size on instructor participation, which is suggested by prior study [17] and confirmed in model (2), mainly attributes to that of instructor replying. As class size increases, the positive effect of instructor replying on student participation decreases and the advantage of instructor posting over replying in leveraging student participation become stronger.

Overall, while instructors participate mostly through replying (i.e., $90 \%$ of instructor participation activities), posting is more effective in enhancing student participation. Instructors should shift their participation towards posting to optimize their time and effort for a maximum effect on student participation. This is particularly important as class size increases.

Moreover, as class size is the key feature that distinguish MOOCs from online courses studied in prior research on instructor participation, we are interested in further understanding the relationship between class size and student participation. Prior research suggests that larger class sizes allow for more interactions between students and more diverse topics for discussion, thus class size may positively affect student participation [42-43]. This is empirically shown in studies on online courses of relatively small size [17] as well as in this study on MOOCs (i.e., the parameter estimation of lnClassSize is significantly positive). However, as the class size of MOOCs can become massive, i.e., with hundreds of thousands of students in a class in our sample, the positive linear relationship between class size and student participation may not be accurate.

To explore a nonlinear effect of class size, we follow previous studies [47, 48] to add and test a quadratic term of class size in model (5). The parameter estimation of the quadratic term of class size is significantly negative $(\beta=-0.031)$ and that of the term of class size is significantly positive $(\beta=0.571)$. These indicate an inverted U-shaped curvilinear relationship between class size and student participation, with a peak point at the class size of about 8,840 students. That is, student participation increases with the increase of class size for the MOOCs of less than 8,840 students. For large MOOCs with more than 8,840 students, student participation decreases with the increase of class size. The inverted U-shaped relationship is depicted in Figure 2.

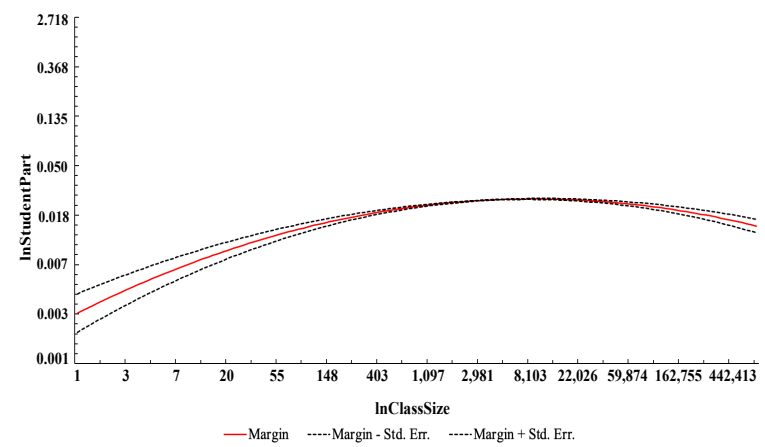

Figure 2. The inverted $U$-shaped relationship between class size and student participation 


\section{Discussion}

This research sheds light on instructors' online participation strategy in terms of posting and replying. Instructors can proactively participate in online discussion forums by posting to lead and direct student discussions, or they can reactively participate by replying and responding to student posts. Empirical results of analyzing a total of $64,434,238$ online forum posts/replies of instructors and students in 16,748 classes of 4,629 MOOCs indicate that (1) instructors participate mainly through replying; (2) both instructor posting and instructor replying enhance student participation, but the effect of instructor posting is stronger than that of instructor reply; and (3) class size negatively moderates the positive effect of instructor replying on student participation in online discussion forums, but not the effect of instructor posting. As a result, the advantage of instructor posting over instructor replying expands with the increase of class size. Additionally, this research reports an inverted Ushaped curvilinear relationship between class size and student participation.

\subsection{Research implications}

This study offers several important implications for research. First, this study extends the examination of the effect of instructor participation on student participation from traditionally studied small-sized online courses (i.e., less than 50 students) to MOOCs of massive class size, and confirms the effectiveness of instructor participation in fostering student participation in the setting of MOOCs. Large class size poses significant challenges to students' as well as instructors' participation in online discussion forums [14]. As class size increases, the demand for and complication of instructor participation in online discussion forums can dramatically increase. In MOOCs that typically have thousands to tens of thousands of students in a class, participation in online forums can become time and energy consuming for instructors. Confirming the effect of instructor participation in such settings provides empirical supports to instructors' efforts.

Moreover, this research advances our understanding of instructor participation in online discussion forums by detangling and inquiring into the effects of instructor posting and instructor replying. Prior research focused on examining the frequency of instructor participation but did not separate the different modes of instructor participation [1, 17]. Instructor posting and instructor replying in online course discussion forums are two genres of instructor participation, serving different interaction functions, steering towards different discussion orientations, and manifesting instructor presence differently. By separating the two and studying their differential effects, this research adds to the literature and our knowledge on instructor participation strategy. The results on the more frequent activity of instructor replying, the stronger positive effect of instructor posting over instructor replying, as well as the negative moderation of class size on the positive effect of instructor replying on student participation provide useful insights into the effectiveness of instructor participation and also implicates the importance of studying how instructors participate, instead of the total number of their activities.

\subsection{Practical implications}

The findings of this study have important implications for online course instructors as well as MOOCs platforms. Participating in online forums and interacting with students are important tasks for instructors of online courses, but can be challenging and time-consuming, particularly with large classes. Despite their commitment and desire to help students in the learning process, instructors are limited in their time and resources and need to identify better approaches to optimize their efforts and maximize the educational results. This research suggests that instructors need to separate posting and replying as two approaches of online discussion forum participation and consider their differential functions and effects in their online interaction plan.

Particularly, the results suggest that the common practice of instructor participation may be sub-optimal and need attention and adjustment. Data in our sample reveals that instructors mainly participate in online discussion forums through replying; the frequency of replying is about nine times of the frequency of posting. This is understandable in that instructors may be more prone to responding to student questions and comments, instead of being more proactive and directive in online discussion forums. However, our results also indicate that posting can be more effective than replying in fostering student participation, particularly with the increase of class size. MOOCs instructors can significantly benefit from shifting towards postingfocused online participation, which requires a sound plan beforehand. MOOCs platforms may consider our results and incorporate metrics and supporting tools to help instructors better gauge their online participation activities to achieve the best results.

\subsection{Limitations and future directions}

This research has the following limitations, which could inform future research. First, the empirical study was carried out with a dataset of MOOCs offered in 
Chinese and within a specified class duration range on a Chinese MOOCs platform. Studies in other online course settings, such as in a different language setting and with a different class duration range, can be conducted to validate our results and increase the generalizability of the findings.

While inquiring into the participation strategy, this research focuses on the two modes of instructor participation in online discussion forums, i.e., new posts vs. replies to student posts, but does not look into their contents such as instructional or social interactions [3]. Future research can combine the mode/format types and content of instructor participation in study to further understand their respective and combined effects on student participation. Such knowledge can effectively enrich and guide instructors' online participation.

This study focuses on the frequency of student participation in evaluating the effect of instructor participation, and in this regard, indicates the importance of posting over replying in instructor participation. However, prior research suggests that an instructor activity often has differential effects on various aspects of the student learning experience. For example, while instructors' conversational interaction does not improve students' perceptions of their learning, it can improve students' perceptions of instructor and course quality [19]. As this research employs secondary data, it is restricted to existing measures available in the MOOCs dataset on student participation. Future research could test the effect of instructors posting and replying on multiple dimensions of the student experience, to develop a comprehensive understanding of their effects and guide instructors' course engagement strategies.

\section{Conclusions}

This research studies how instructor participation in online discussion forums, in terms of posting vs. replying, may affect student participation in MOOCs. Empirical results from analyzing online discussion forum participation data of 16,748 classes of 4,629 MOOCs show that instructors mainly participate in online discussion forums by replying, rather than posting. Both instructor posting and instructor replying positively affect student participation, with the former generating a higher impact. Class size negatively moderates the positive effects of instructor replying, but not that of instructor posting. That is, as class size increases, the advantage of instructor posting over replying expands. These findings suggest the importance of a well-planned online participation strategy for instructors to optimize the results of their efforts. In general, MOOC instructors should shift away from the current practice of frequent replying, and increase the frequency of posting to direct student discussions. This shift is particularly important in larger-sized MOOCs.

\section{Acknowledgements}

This paper is supported by the National Natural Science Foundation of China (71901030), the fund of the key laboratory of rich-media knowledge organization and service of digital publishing content (ZD2020/09-07), and the Fundamental Research Funds for the Beijing Sport University (2020048).

\section{References}

[1] Mazzolini M, Maddison S. When to jump in: The role of the instructor in online discussion forums. Computers \& Education. 2007: 49(2): 193-213.

[2] Zhang C, Chen H, Phang CW. Role of instructors' forum interactions with students in promoting MOOC continuance. Journal of Global Information Management. 2018; 26(3): 105-120.

[3] Kang M, Im T. Factors of learner-instructor interaction which predict perceived learning outcomes in online learning environment. Journal of Computer Assisted Learning. 2013; 29(3): 292301.

[4] Majid S, Yang P, Lei H, Haoran G. 2014, November. Knowledge sharing by students: Preference for online discussion board vs face-toface class participation. In International conference on Asian digital libraries (pp. 149159). Springer, Cham.

[5] Palmer S, Holt D, Bray S. Does the discussion help? The impact of a formally assessed online discussion on final student results. British Journal of Educational Technology. 2008; 39(5): 847-858.

[6] Wei HC, Peng H, Chou C. Can more interactivity improve learning achievement in an online course? Effects of college students' perception and actual use of a course-management system on their learning achievement. Computers \& Education. 2015; 83(April): 10-21.

[7] Brooks C, Greer J, Gutwin C. The data-assisted approach to building intelligent technologyenhanced learning environments. In Learning analytics. Springer, New York, NY. 2014; 123156.

[8] Peters VL, Hewitt J. An investigation of student practices in asynchronous computer conferencing courses. Computers \& Education. 2010; 54(4): 951-961.

[9] Almatrafi O, Johri A. Systematic review of discussion forums in massive open online courses 
(MOOCs). IEEE Transactions on Learning Technologies. 2018; 12(3): 413-428.

[10] Sharif A, Magrill B. Discussion forums in MOOCs. International Journal of Learning, Teaching and Educational Research. 2015; 12(1): 119-132.

[11] Wise AF, Speer J, Marbouti F, Hsiao YT. Broadening the notion of participation in online discussions: examining patterns in learners' online listening behaviors. Instructional Science. 2013; 41(2): 323-343.

[12] Peterson AT, Roseth CJ. Effects of four CSCL strategies for enhancing online discussion forums: social interdependence, summarizing, scripts, and synchronicity. International Journal of Educational Research. 2017; 76: 147-161.

[13] Hew KF. Student perceptions of peer versus instructor facilitation of asynchronous online discussions: Further findings from three cases. Instructional Science. 2015; 43(1): 19-38.

[14] Jiang M, Ting E. A study of factors influencing students' perceived learning in a web-based course environment. International Journal of Educational Telecommunications. 2000; 6(4): 317-338.

[15] Murphy CA, Fortner RA. 2014. Impact of instructor intervention on the quality and frequency of student discussion posts in a blended classroom. MERLOT Journal of Online Learning and Teaching. 2014; 10(3): 337-350.

[16] Wise K, Hamman B, Thorson K. Moderation, response rate, and message interactivity: Features of online communities and their effects on intent to participate. Journal of Computer-Mediated Communication. 2006; 12(1): 24-41.

[17] Parks-Stamm EJ, Zafonte M, Palenque SM. The effects of instructor participation and class size on student participation in an online class discussion forum. British Journal of Educational Technology. 2017; 48(6): 1250-1259.

[18] Arbaugh JB. Sage, guide, both, or even more? An examination of instructor activity in online MBA courses. Computers \& Education. 2010; 55(3): 1234-1244.

[19] Hoey R. Examining the characteristics and content of instructor discussion interaction upon student outcomes in an online course. Online Learning. 2017; 21(4), 263-281.

[20] Benton S, Li D, Brown R, Guo M, Sullivan P. Revising the IDEA Student Ratings of Instruction System: 2002-2011 Data. IDEA. 2015.

[21] Bonafini, F., Chae, C., Park, E., \& Jablokow, K. (2017). How much does student engagement with videos and forums in a MOOC affect their achievement? Online Learning Journal, 21(4).
[22] $\mathrm{Hu} \mathrm{PJH}$, Hui W. Examining the role of learning engagement in technology-mediated learning and its effects on learning effectiveness and satisfaction. Decision Support Systems. 2012; 53(4): 782-792.

[23] Oh EG, Huang WHD, Mehdiabadi AH, Ju B. Facilitating critical thinking in asynchronous online discussion: comparison between peer-and instructor-redirection. Journal of Computing in Higher Education. 2018; 30(3): 489-509.

[24] Carswell L, Thomas P, Petre M, Price B, Richards M. Distance education via the Internet: The student experience. British Journal of Educational Technology. 2000; 31(1): 29-46.

[25] Romiszowski A, Mason R. Computer-mediated communication in Jonassen, David H. [ed.]: Handbook of research for educational communications and technology. 2004.

[26] Schrire S. Knowledge building in asynchronous discussion groups: Going beyond quantitative analysis. Computers \& Education. 2006; 46(1): 4970.

[27] Hew KF, Cheung WS. Attracting student participation in asynchronous online discussions: A case study of peer facilitation. Computers \& Education. 2008; 51(3): 1111-1124.

[28] Deng L, Tavares NJ. From Moodle to Facebook: Exploring students' motivation and experiences in online communities. Computers \& Education. 2013; 68(October): 167-176.

[29] Phirangee K, Epp CD, Hewitt J. Exploring the relationships between facilitation methods, students' sense of community and their online behaviors. Online Learning. 2016; 20(2): 134-154.

[30] Tello SF. An analysis of student persistence in online education. In Information communication technologies: Concepts, methodologies, tools, and applications. IGI Global. 2008; 1163-1178.

[31] Rourke L, Anderson T. Exploring social communication in computer conferencing. Journal of Interactive Learning Research. 2002; 13(3): 259-275.

[32] Cho V, Littenberg-Tobias J. Digital devices and teaching the whole student: developing and validating an instrument to measure educators' attitudes and beliefs. Educational Technology Research and Development. 2016; 64(4): 643-659.

[33] Mazzolini, M., \& Maddison, S. Sage, guide or ghost? The effect of instructor intervention on student participation in online discussion forums. Computers \& Education. 2003; 40(3): 237-253.

[34] Park JH, Schallert DL, Sanders AJ, Williams KM, Seo E, Yu LT, Vogler JS, Song K, Williamson ZH, Knox MC. Does it matter if the teacher is there?: A teacher's contribution to emerging patterns of 
interactions in online classroom discussions. Computers \& Education. 2015; 82(March): 315 328.

[35] Rieber LP. Participation patterns in a massive open online course (MOOC) about statistics. British Journal of Educational Technology. 2017; 48(6): 1295-1304.

[36] Deboer J, Ho AD, Stump GS, Breslow L. Changing "course". Educational Researcher. 2014; 43(2): 74-84.

[37] Balakrishnan G, Coetzee D. Predicting student retention in massive open online courses using hidden markov models. Electrical Engineering and Computer Sciences, University of California at Berkeley. Technical Report UCB/EECS-2013109. 2013; 53, 57-58.

[38] Gillani N, Eynon R. Communication patterns in massively open online courses. The Internet and Higher Education. 2014; 23(October): 18-26.

[39] Howley I, Tomar GS, Ferschke O, Rosé CP. Reputation systems impact on help seeking in mooc discussion forums. IEEE Transactions on Learning Technologies. 2017; 1.

[40] Zhang, DJ, Allon G, Van Mieghem JA. Does social interaction improve learning outcomes? Evidence from field experiments on massive open online courses. Manufacturing \& Service Operations Management. 2017; 19(3): 347-367.
[41] Xu B, Yang D. Study partners recommendation for xMOOCs learners. Computational Intelligence and Neuroscience, 2015; 832093.

[42] Caspi A, Gorsky P, Chajut E. The influence of group size on nonmandatory asynchronous instructional discussion groups. The Internet and Higher Education. 2003; 6(3): 227-240.

[43] Hew KF, Cheung, WS. Higher-level knowledge construction in asynchronous online discussions: An analysis of group size, duration of online discussion, and student facilitation techniques. Instructional Science. 2011; 39(3): 303-319.

[44] Latif E, Miles S. Class attendance and academic performance: A panel data analysis. Economic Papers: A journal of applied economics and policy. 2013; 32(4), 470-476.

[45] Blackwell III JL. Estimation and testing of fixedeffect panel-data systems. The STATA journal. 2005; 5(2), 202-207.

[46] Cohen J. A power primer. Psychological Bulletin. 1992; 112: 155-159.

[47] Beyene, J, Moineddin, R. Methods for confidence interval estimation of a ratio parameter with application to location quotients. BMC Medical Research Methodology. 2005; 5(1), 1-7.

[48] Lind, JT, Mehlum, H. With or without U? The appropriate test for a U-shaped relationship. Oxford bulletin of economics and statistics. 2010; 72(1), 109-118. 